\title{
Design Considerations for a Crewed Mars Ascent Vehicle
}

\author{
Michelle A. Rucker ${ }^{1}$ \\ National Aeronautics and Space Administration, Lyndon B. Johnson Space Center, Houston, Texas, 77058
}

\begin{abstract}
Exploration architecture studies identified the Mars Ascent Vehicle (MAV) as one of the largest "gear ratio" items in a crewed Mars mission. Because every kilogram of mass ascended from the Martian surface requires seven kilograms or more of ascent propellant, it is desirable for the MAV to be as small and lightweight as possible. Analysis identified four key factors that drive MAV sizing:
\end{abstract}

1) Number of crew: more crew members require more equipment-and a larger cabin diameter to hold that equipment-with direct implications to structural, thermal, propulsion, and power subsystem mass.

2) Which suit is worn during ascent: Extravehicular Activity (EVA) type suits are physically larger and heavier than Intravehicular Activity (IVA) type suits and because they are less flexible, EVA suits require more elbow-room to maneuver in and out of. An empty EVA suit takes up about as much cabin volume as a crew member.

3) How much time crew spends in the MAV: less than about 12 hours and the MAV can be considered a "taxi" with few provisions for crew comfort. However, if the crew spends more than 12 consecutive hours in the MAV, it begins to look like a Habitat requiring more crew comfort items.

4) How crew get into/out of the MAV: ingress/egress method drives structural mass (for example, EVA hatch vs. pressurized tunnel vs. suit port) as well as consumables mass for lost cabin atmosphere, and has profound impacts on surface element architecture.

To minimize MAV cabin mass, the following is recommended: Limit MAV usage to 24 consecutive hours or less; discard EVA suits on the surface and ascend wearing IVA suits; Limit MAV functionality to ascent only, rather than dual-use ascent/habitat functions; and ingress/egress the MAV via a detachable tunnel to another pressurized surface asset.

$\begin{array}{lll}g & \text { Nomenclature } \\ \mathrm{kg} & =\text { Earth standard gravitational force } \\ \mathrm{kN} & =\text { kilogram } \\ \mathrm{m} & =\text { meter } \\ \mathrm{m}^{3} & =\text { cubic meters }\end{array}$

\section{Introduction}

Crewed Mars Ascent Vehicle (MAV) designs fall into one of two broad categories: 1) a relatively large habitable variant that serves as both ascent vehicle and habitat, either on the surface or in orbit; or 2) a much smaller taxi variant used only for a few hours during the actual ascent. The taxi variant requires another Mars surface asset for habitation. Note that in some architectures, the Mars ascent vehicle might also be used as the crew's descent vehicle.

Ascent vehicles are generally regarded as the largest "gear ratio" item in a given architecture; in other words, every kilogram of an ascent vehicle needs more Earth-launched mass to do its job than most other architecture elements need. Even if ascent propellant can be manufactured on Mars, current technologies still require the ascent vehicle — and the propellant manufacturing plant—be launched from Earth, transported to and then descended onto

${ }^{1}$ Engineer, Exploration Integration and Science Directorate, Mail Stop XM. 
Mars, all of which entails a considerable amount of transit and descent propulsion mass. The overall gear ratio depends on end-to-end mission architecture. Analysis performed by the National Aeronautics and Space Administration (NASA) estimates that the amount of propellant needed to boost a single kilogram of ascent vehicle to a 1-sol Mars orbit ranges between $3.5 \mathrm{~kg}$ (for an ideal rocket) to as much as $15 \mathrm{~kg}$ for a stage mass fraction of 0.73. For the purpose of this exercise, the ascent gear ratio was assumed to be at the lower end of the range, or 7:1 (seven kilograms of ascent propellant to boost every one kilogram of MAV inert mass).

\section{Factors That Drive Cabin Size}

Clearly, the smaller the ascent vehicle, the lower the overall Earth-launched mass will be, which often means lower mission cost. Although many factors will affect a final MAV design, there are at least four key drivers for MAV cabin size: number of crew, what the crew is wearing during ascent, how much time crew spends in the MAV, and how crew get into or out of the MAV

\section{A. Number of Crew}

The number of crew drives MAV size both directly (more crew require a larger cabin volume) and indirectly (a larger cabin requires more thermal protection and longer avionics cables, which in turn requires more power mass, all of which drives ascent propellant load). For the purpose of this exercise, it was assumed that at least two crew members would land on Mars in even the most minimalist scenario, and the maximum crew complement would be limited by the Orion return vehicle, which is sized for up to six.

More crew members simply require more physical elbow room. Work done as part of the Constellation Program's Altair Lunar Lander project ${ }^{1}$ concluded that four standing crew members packed quite close together only need about a $1.8 \mathrm{~m}$ diameter cabin for a short duration ascent. Six crew obviously require more (Figure 1), probably at least a $2.2 \mathrm{~m}$ diameter cabin. Two crew members would require less volume, possibly as low as a $1.58 \mathrm{~m}$ diameter cabin. Note that many factors could increase taxi cabin diameter. For example, if crew ascend in recumbent seats (rather than standing up) or will be performing active piloting, then a larger cabin will be required. In any case, the structural mass difference between $1.58 \mathrm{~m}$ and $2.2 \mathrm{~m}$ diameter crew cabins could be quite significant.

At $82.2 \mathrm{~kg}$ for a $50^{\text {th }}$ percentile male crew member ${ }^{2}$, a six-crew MAV has to carry at least $328.8 \mathrm{~kg}$ more load than a two-crew MAV. With $95^{\text {th }}$ percentile male crew, the difference grows to $394 \mathrm{~kg}$. If each kilogram of MAV mass requires just seven kilograms of ascent propellant to reach a one-sol orbit, that extra 328 to $394 \mathrm{~kg}$ of crew will require as much as $2,758 \mathrm{~kg}$ more ascent propellant, which in turn requires larger propellant tanks and more structural support.

In addition to the crew, the MAV cabin must also accommodate crew equipment, even for short ascent durations. At a minimum, each crew member will need either a Portable Life Support System (PLSS) or an oxygen umbilical for cabin depressurization contingencies. At as much as $0.75 \mathrm{~m} \times 0.56 \mathrm{~m} \mathrm{x} 0.254 \mathrm{~m}$ for a PLSS, or $0.127 \mathrm{~m}$ diameter $\times 4.58 \mathrm{~m}$ long for even a short Intravehicular (IVA) oxygen umbilical, equipment volume quickly adds up, especially for six crew members. If the crew must remain inside the MAV for more than a few hours, additional equipment will be required (discussed below).

One obvious way to reduce MAV mass is to remove the pressure cabin altogether, such as the concept shown in Figure 2. Although this can reduce structural, thermal, and power mass, there are a number of disadvantages. An unpressurized MAV would require crew to remain in their Extravehicular Activity (EVA) suits, which is currently untenable for a lengthy (more than 24 hour) ascent. Ascending in EVA suits contaminated with surface dust also poses the problem of planetary protection, which will require suit decontamination before the crew transfers into their transit vehicle (and further extends the time crew must remain in their suits). With no shell between the crew and the MAV's reaction control system thrusters, EVA suit contamination is another concern because thruster plumes may damage the suits or
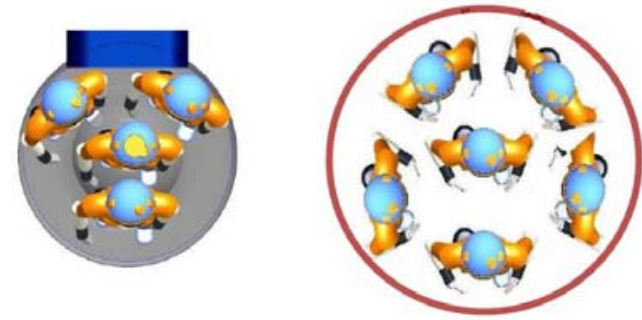

Figure 1. Top view of Cabin: four vs. six crew.

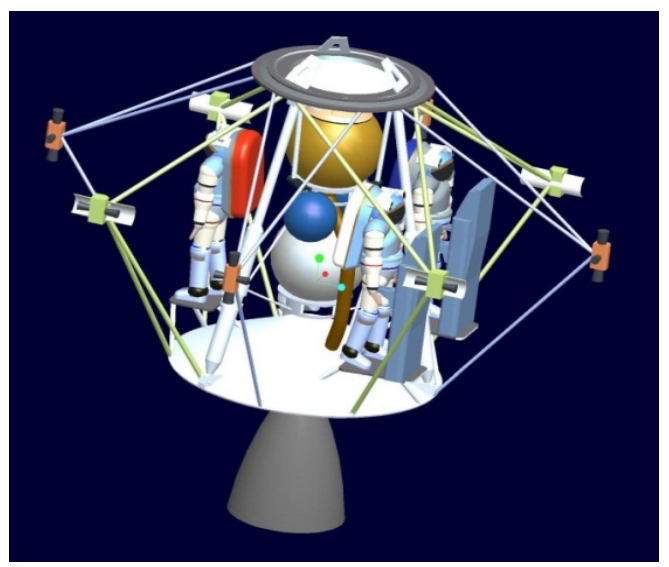

Figure 2. Unpressurized ascent vehicle concept. 
deposit toxic contaminants that can then be transferred into the destination vehicle. Although eliminating the pressure cabin eliminates the mass of a pressurized docking system, this requires an EVA transfer into the orbiting transit habitat, which could be risky in the event of an incapacitated crew member. This concept precludes dual use of the MAV for surface habitation, forcing the architecture to carry a separate pressurized surface element. What's more, an unpressurized MAV cannot be used as a temporary safe-haven in a surface contingency. All of these issues can be mitigated, but the mass penalties may outweigh the benefits.

\section{B. IVA vs. EVA Suits}

Due to the possibility of a sudden cabin depressurization it is generally assumed that crew members will ascend in either EVA or IVA suits. The choice of ascent suit can impact MAV cabin size not only because the EVA suits are physically larger than the IVA suits (Figure 3), but also because EVA suits will likely be contaminated with surface dust which will require additional equipment to control.

Cabin mockup testing ${ }^{1}$ identified the EVA suit's bulky design as a potential cabin configuration driver. For example, even with their PLSS's removed, pilots were unable to stand side by side in a $2.35 \mathrm{~m}$ diameter cylindrical vehicle without contact between their suit's PLSS plates (Figure 4). This potentially drives the placement or size of piloting controls, windows, and other equipment.

Simulated microgravity testing performed during the Constellation Program also identified problems passing a large, pressurized EVA suit through the docking system hatch tunnel ${ }^{3}$. The workaround would have required EVA transfer between the Altair lunar lander and Orion in the event of an ascent vehicle depressurization. Since testing found no issues with the IVA suits, this contingency EVA-as well as the need for even longer EVA umbilical hoses stowed in the MAV - can be avoided on a Mars ascent simply by switching the crew into their IVA suits prior to ascent.

EVA suits also pose a significant ascent mass penalty over the IVA suits. At roughly $75 \mathrm{~kg}$ difference between an IVA and EVA suit (not including the PLSS), the mass penalty

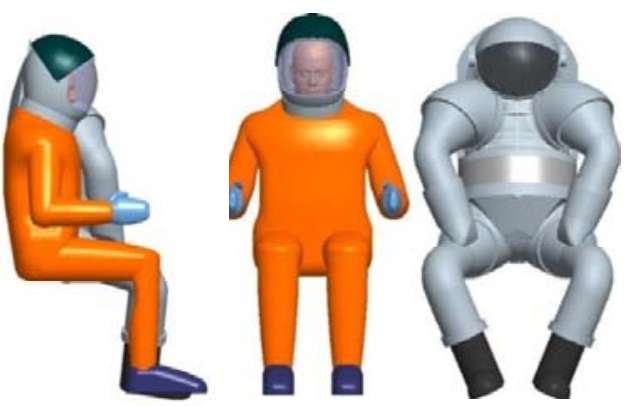

Figure 3. Size comparison of IVA (orange) and EVA (white) space suit Concepts

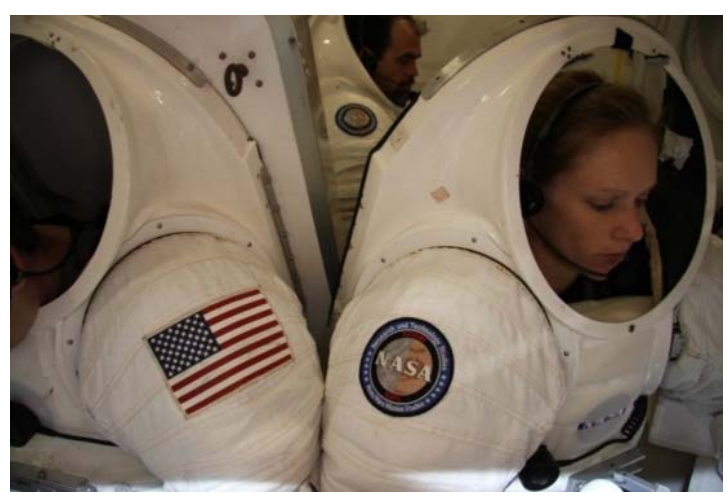

Figure 4. EVA suit contact in curved cabin for six crew members is about $450 \mathrm{~kg}$; with the 7:1 propellant ratio, that difference adds another 3,150 $\mathrm{kg}$ of propellant (plus larger propellant tanks, more tank structure, etc.) simply to accommodate the larger suits.

The downside to acending in IVA suits is that it requires the crew to discard their EVA suits on the surface. This poses an immediate problem of how to switch from EVA to IVA suits in a small cabin, and then get the EVA suits out of the MAV before ascent. Leaving the suits behind also means that at least two fresh EVA suits would have to be available on the in-space return vehicle for EVA contingencies, adding to the overall mission cost. On the other hand, planetary protection is simplified if surface EVA suits can be kept out of the MAV altogether, as this eliminates the need to scrub Mars regolith from the suits or MAV cabin atmosphere, which would require additional MAV equipment mass.

Ascending in IVA suits poses one significant risk: in the event of a MAV-to-transfer vehicle docking failure, the crew cannot simply exit a side hatch and translate externally because the IVA suits do not provide sufficient thermal protection for EVA excursions. Several workarounds have been proposed, including a thermal "overcoat" that could be used for brief, emergency EVA exposure. Another approach is to break the contingency down into more manageable parts, and look at the three failure possibilities: 1) the MAV docks, but the docking hatch becomes jammed; 2) the MAV can soft-dock, but not hard-dock; or 3) the MAV cannot even soft-dock. In the event the MAV fails to soft-dock, the MAV may be too far from the transit vehicle for an EVA transfer anyway, regardless of which suits the crew is wearing. The program will have to either accept the potential crew safety risk, or explore grapple fixtures, jet-packs, or other means to mitigate this risk before the suit decision comes into play. In the event the MAV can soft-dock, but not hard-dock, crew will still be able to translate through the unpressurized docking tunnel in their IVA suits as long as their umbilical hoses are long enough. Finally, the jammed docking hatch contingency 
was addressed in previous studies by assuming the MAV carried a jammed hatch tool kit, estimated at about five kilograms mass penalty.

\section{MAV Mission Duration}

Preliminary ascent timelines to a one-sol orbit estimate that crew must remain in the MAV for up to 43 hours, assuming a single missed launch opportunity. Crew time inside the MAV could be minimized by ascending to a lower orbit, or eliminating the missed launch contingency assumption altogether. Including pre-ascent vehicle preparations though, crew is likely to be inside the MAV for at least 24 hours. If the MAV ascends to a higher orbit, or serves double-duty as a short surface stay habitat, the crew may be living/working in the MAV for up to a week.

How long the crew must remain in the MAV greatly impacts MAV mass. If the crew only has to be inside for a few hours, they can remain in their spacesuits, with the limiting factor likely the Maximum Absorbency Garment (MAG), currently rated for eight hours. Materials and design modification may be able to extend operational use a few more hours but current designs require spacesuit doffing to replace a soiled MAG. Because the Constellation Program required ${ }^{4}$ Orion to sustain suited crew in an unpressurized cabin for several days in a worst-case contingency, extended in-suit waste management is a NASA technology goal ${ }^{5}$. Until then, a practical limit of 12 to 24 hours for nominal (planned) operations is a reasonable assumption.

If crew are inside the MAV long enough that they need to replace soiled MAGs, MAV cabin diameter will grow dramatically. First, there is the problem of doffing suits. NASA's Human Integration Design Handbook ${ }^{6}$ recommends 6.35 cubic meters $\left(\mathrm{m}^{3}\right)$ for Space Shuttle-style EVA suit don/doff in micro-gravity. Cabin mockup testing performed as part of the Altair project ${ }^{7}$ confirmed that suit don/doff was a significant cabin volume driver (and may be more pronounced in a surface gravity field than in micro-gravity). Note that new rear-entry EVA suit concepts require a crew member to pull him/herself up and out of the suit, which drives cabin ceiling height. IVA type suits require a bit less volume to don/doff.

Once the suits are removed, the immediate problem of suit stowage must be addressed. As noted, EVA suits are bulkier than IVA suits, but a suit takes up about as much cabin volume as a crew member. In the worst-case, if all six crew members have to remove their EVA suits, the MAV must essentially be sized as a 12-crew pressure cabin (Figure 5). MAV volume could be optimized for ascent if crew stagger suit don/doff, so that only one crew member is out of their suit at any given time, but this workaround isn't practical if the MAV is used for surface habitability as well as for ascent, unless the MAV is mated to another pressurized element on the surface such as an airlock or habitat.

To prevent damage to the suits, it is preferable to place them in stowage bags. The working assumption for early Constellation Program studies was $1.04 \mathrm{~m}^{3}$ volume per EVA suit, with each stowage bag estimated to be $14.55 \mathrm{~kg}$. Once suits have been doffed and stowed, the next concern is waste and hygiene. Privacy for removing soiled MAGs could be provided with a simple curtain at relatively small volume penalty. Volume needed to dispose of soiled MAGs will

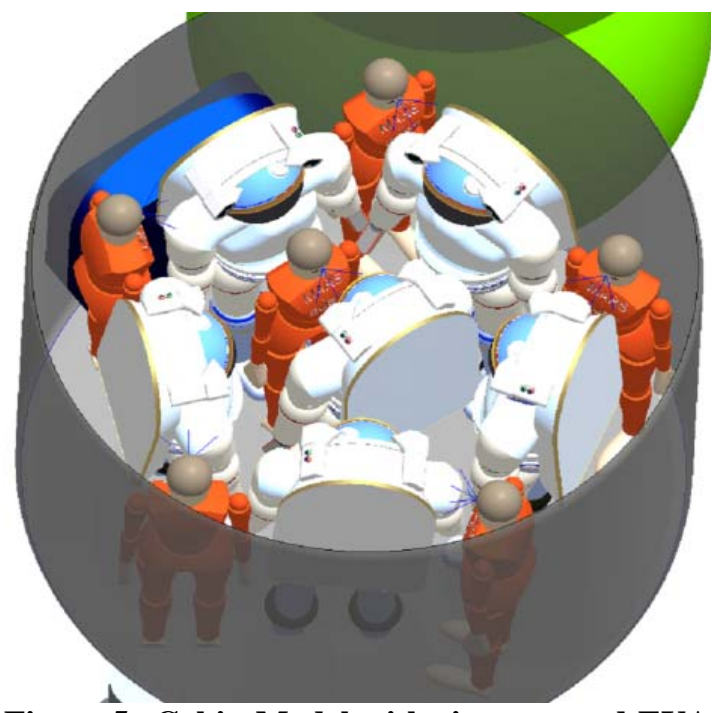

Figure 5. Cabin Model with six crew and EVA suits depend on how long the crew must remain inside the MAV—a trash bag is probably sufficient for a single day, but longer durations will require more elaborate disposal methods to minimize cabin odor and contamination. Per NASA-STD- $3001^{8}$ a six-crew cabin would accumulate about 54 liters of urine after just three days. At that point, a rudimentary toilet may trade well for mass and stowage volume.

Using the MAV for surface habitability will dramatically increase MAV size, with sleeping expected to be a key driver. NASA's Human Integration Design Handbook ${ }^{6}$ recommends $2.69 \mathrm{~m}^{3}$ per crew member for activities such as sleeping and sheltering. Although sleep bunks can be stacked vertically to save floor space, the cabin has to be at least as wide as the tallest crew member to avoid forcing the crew to sleep in a fetal position or on an incline.

One option for reducing MAV diameter may be to limit surface crew stature. For example, the difference between $50^{\text {th }}$ and $95^{\text {th }}$ percentile male crew statures is about $10.2 \mathrm{~cm}$ (Table 1). Accounting for cabin curvature, this change would drop the

Table 1. Crew mass and stature comparison

\begin{tabular}{|c|c|c|}
\hline & \multicolumn{2}{|c|}{ Stature per NASA SSP 50005 } \\
\hline Percentile & Female & Male \\
\hline 5th & $148.9 \mathrm{~cm}$ & $169.7 \mathrm{~cm}$ \\
\hline 50th & $157.0 \mathrm{~cm}$ & $179.9 \mathrm{~cm}$ \\
\hline 95th & $165.1 \mathrm{~cm}$ & $190.1 \mathrm{~cm}$ \\
\hline
\end{tabular}


internal cabin diameter from at least $2.06 \mathrm{~m}$ to about $1.885 \mathrm{~m}$ diameter. Although that may seem insignificant, extended over a $3 \mathrm{~m}$ cabin height this simple change translates to an internal cabin volume reduction of more than $1.6 \mathrm{~m}^{3}$, and a cabin barrel section surface area savings of about $1.65 \mathrm{~m}^{2}$, both of which offer flow-down savings to structures, power, thermal protection, and life support subsystems-all multiplied by the 7:1 propellant gear ratio. Although limiting crew stature would prompt lively debate, to put things into perspective it should be noted that the Apollo 11 surface crew fall just under the $50^{\text {th }}$ percentile stature definition by current NASA standards.

Although sleep bunks can be folded up during waking hours to extend working volume, there is still the problem of where to stow equipment at night. Food, clothing, hygiene supplies, a first aid kit, science equipment, and EVA consumables (MAGs, spare gloves, etc.) must all be stowed inside the habitable volume, along with vehicle equipment such as piloting controls and displays, power interface panels, or crew umbilical hoses. Figure 6 gives an idea of how much equipment is required to support six crew members for a week on the surface, in a Habitable MAV.

Another factor that could affect MAV sizing is whether the crew also descends to the surface inside the MAV. If descending in the MAV, the crew will almost certainly need recumbent seats (Figure 7) for protection. Cabin volume for seats themselves must be accounted for in cabin sizing, as well as descent and ascent propellant loads needed for seat mass. MAV engineering analysis typically assumes the crew can stand during ascent (a hold-over from Constellation Program concepts), but the decision will ultimately hinge on crew safety. Preliminary estimates for a 3,623 kg crew cabin, with 0.80 stage mass fraction, and $100 \mathrm{kN}$ thrust engines is about $1.5 \mathrm{~g}$ at the end of the first stagerelatively gentle compared to the Space Shuttle's lift-off, but potentially dangerous for a crew that's spent more than 500 days at reduced Martian gravity following a six month transit in microgravity.

Orion-type recumbent seats, sized for Earth re-entry, are estimated at up to $27 \mathrm{~kg}$ each, but lower mass seats may be adequate for Mars ascent or descent. Note that seats may be removed from the MAV after landing (unless they are needed during ascent), but this may drive MAV cabin hatch design. To reduce overall landed mass, common seating might be shared between the MAV and surface rovers, though again that may drive either seat or hatch design to allow seat relocation between the two vehicles.

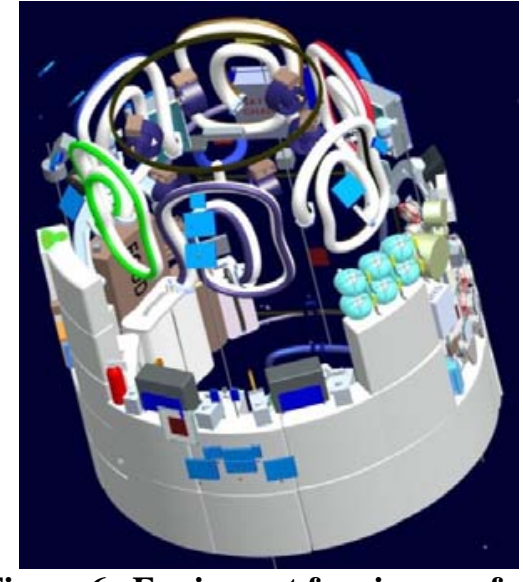

Figure 6. Equipment for six crew for a week

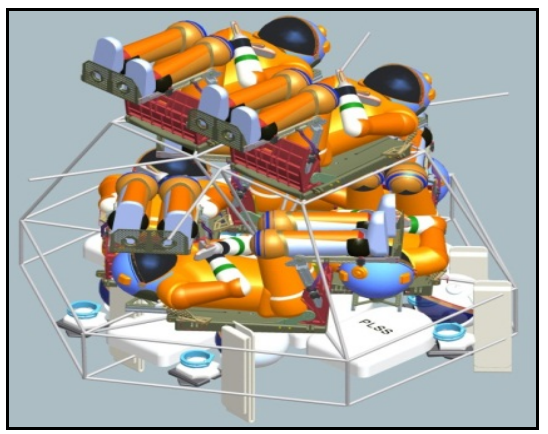

Figure 7. Six crew in recumbent seats

Finally, some consideration must be given to return cargo, which may be as much as $250 \mathrm{~kg}$. Conventional wisdom says there's no reason to ascend more return cargo than what Orion can accommodate (which may be as low as $100 \mathrm{~kg}$ ), but it's possible that Mars return science samples could be diverted to another destination (an orbiting outpost, for example), or designed for a separate Earth re-entry. To protect science sample integrity, as well as to protect both the crew and Earth from forward contamination, science sample containers must be sealed and decontaminated before entering either the MAV or the orbiting transit vehicle. Returning science samples could be stowed outside the MAV pressure cabin, which eliminates the landed mass penalty for sealing/decontamination equipment. On the other hand, this will require an EVA transfer from the MAV to the Earth transit vehicle, which may result in a net mass increase.

\section{MAV Ingress/Egress}

How the crew gets into or out of the MAV has profound implications on mission element architecture. There are at least five possible ingress/egress operations in a crewed Mars surface mission:

1) Transferring from Orion or an Earth transit vehicle into the MAV in microgravity (if descending in the MAV).

2) Egressing the MAV to perform a surface EVA or transit to another surface asset (such as a habitat) in Mars gravity.

3) Ingressing/egressing the MAV in Mars gravity to retrieve logistics supplies or stow return cargo.

4) Ingressing the MAV in Mars gravity to ascend to Mars orbit.

5) Egressing the MAV in microgravity to return to Orion or the Earth transit vehicle. 
Current ingress/egress methods include EVA hatches, IVA tunnels (Figure 8), and Suit Ports (Figure 9).

There are three key considerations for MAV ingress/egress design. First, which suits will the crew be wearing during ingress/egress? As noted above, a pressurized IVA suit can pass through a standard exploration docking hatch, but a pressurized EVA suit requires a larger hatch. On the other hand, IVA suits are unsuitable for surface operations, and cannot be used with EVA hatches alone. Second, where will crew be changing from IVA to EVA suits, or vice versa? If the MAV is large enough for all crew members to change into their EVA suits, then an EVA hatch is acceptable. But if the MAV isn't large enough to get out of their IVA suits, the crew can't explore the surface or get to another vehicle without a tunnel, suit port, or attached airlock. Finally, how much dust can be tolerated inside the MAV? Apollo experience ${ }^{10}$ warns that opening an EVA hatch directly to the surface will bring surface dust into the ascent vehicle. This will drive MAV cabin design and equipment mass to prevent Martian dust from migrating back into Orion and eventually to Earth, in violation of planetary protection protocols ${ }^{11}$.

\section{EVA Hatch}

EVA hatches have the benefit of relatively low mass and high Technology Readiness Level (TRL). But because an EVA hatch would require MAV depressurization for every ingress/egress, everything in the cabin would have to be rated for extended Mars surface atmosphere exposure, and all crew members would have to suit up even if only one was actually leaving the cabin - which means the MAV would still have to be big enough for all crew members to ingress/egress their suits together. Altair project mockup testing found that even three EVA suited crew could stand together in a relatively small $1.8 \mathrm{~m}$ diameter cabin (Figure 10). However, getting into and out of their EVA suits was hampered by a rear-entry suit design that requires the PLSS hatch to swing open laterally for suit doffing (Figure 11). In practice, this either forces the cabin diameter to grow to accommodate PLSS hatch swing, or it will drive a fundamental design change to the EVA suits. These issues aside, the biggest drawback to an EVA hatch is that it will be more difficult to keep dust out of the MAV or prevent Martian dust from migrating back to Orion, and eventually to Earth.

\section{Suit Port}

Suit ports offer the promise of dust mitigation by keeping dusty suits outside the cabin, but current protocol still requires an EVA hatch to get the suits outside for the first EVA, and back inside after the final EVA. This is primarily because current designs don't provide enough structural support to protect the suits from ascent/descent loads or potential thruster plume impingement. Concepts to address these problems have been proposed, but add even more mass to each suit port (which are already about $100 \mathrm{~kg}$ each). Even if the structural problem is resolved, an EVA hatch is still required for an incapacitated crew member contingency, since it may not be possible to pull an unconscious person up through the suit's rear-entry hatch to safety.

At nearly one meter centerline-to-centerline spacing between suit ports, a small MAV cabin diameter is unlikely to provide sufficient

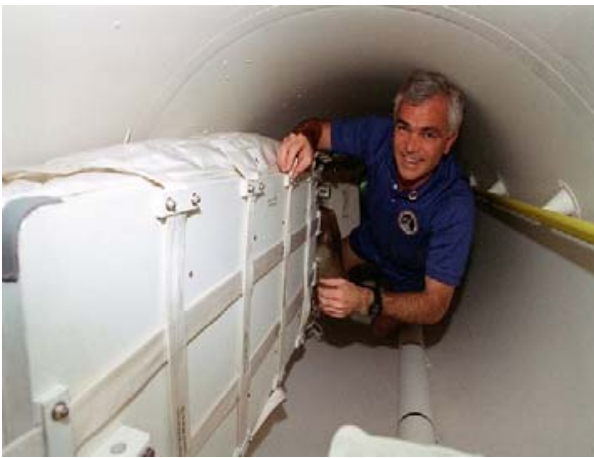

Figure 8. IVA Tunnel

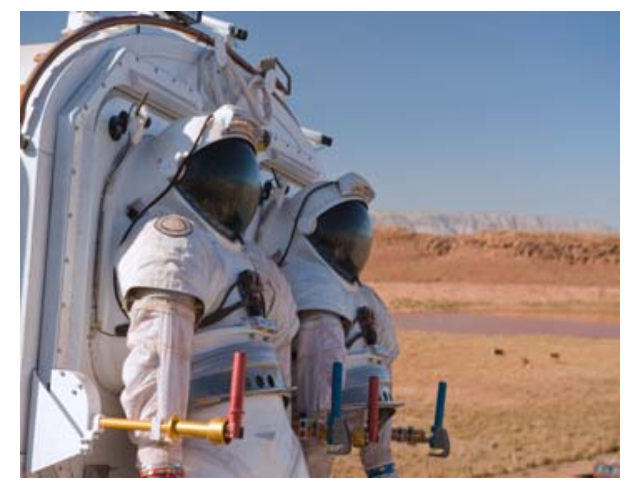

Figure 9. Suit port concept

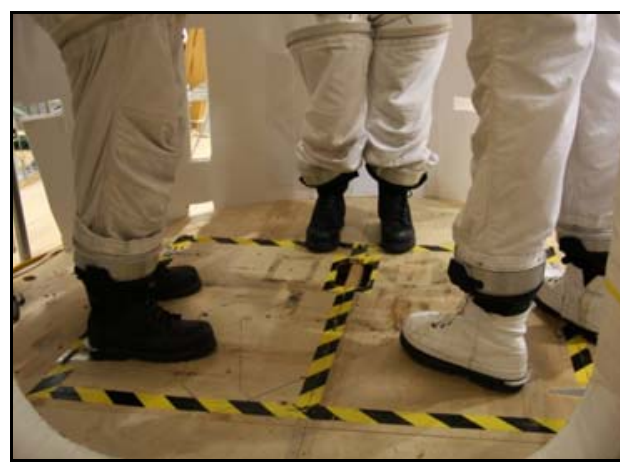

Figure 10. Three crew in $1.8 \mathrm{~m}$ diameter cabin

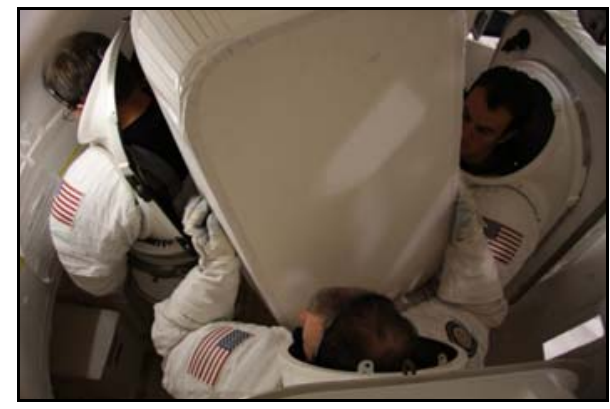

Figure 11. PLSS management issues real estate for more than two suit ports. This poses operational timeline impacts in getting four or six member crews in or out of the vehicle. Crews could ingress two at a time, but once the first two are inside, their suits would have to be removed from the suit ports before the next two crew members could ingress. Once detached from the suit port, 
an empty suit can be damaged if the water inside freezes, which means additional thermal conditioning mass will be needed outside the vehicle for suit stowage-exacerbating what is already a poor mass trade for the suit ports. Worse, to protect against a contingency where the MAV engines fail to ignite and crew need to retreat back to a habitable element, the MAV may have to keep one or two EVA suits attached to its suit ports until lift-off, further adding complexity and mass.

Although suit ports make sense for frequent excursions from a relatively large surface asset (such as a rover or habitat), suit ports do not seem to be a good fit for the MAV.

\section{Tunnel}

For architectures where another element provides habitability function (such as a rover or habitat), or where an airlock module is paired with the MAV, retractable tunnels (Figure 12) are an attractive option. By pushing the suit don/doff and EVA operations to an element that remains on the surface, MAV ascent mass and dust can be minimized. Although a tunnel is likely to pose a significant descended mass impact, the 7:1 propellant penalty does not apply if the tunnel remains on the surface. What's more, retractable tunnels allow surface assets to be re-configured, built up over time, or reconfigured as needed.

Ideally, pressurized tunnels would provide a shirtsleeve crew transfer path between elements. The tunnel

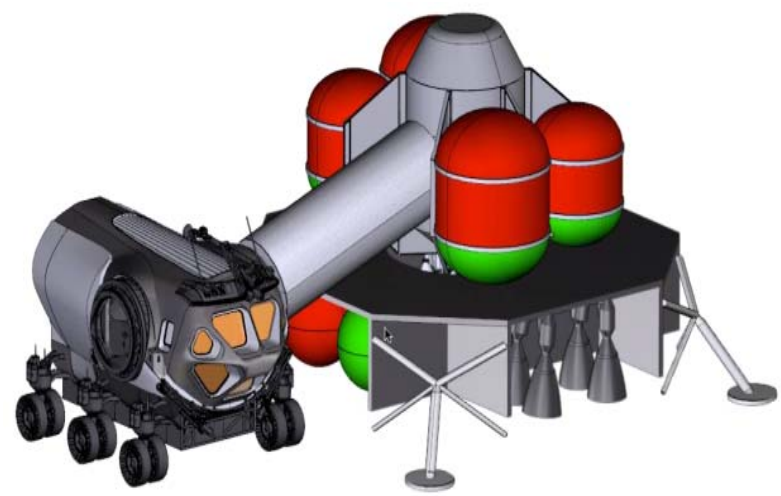

Figure 12. Retractable tunnel from MAV to rover concept may work unpressurized as well, but would require umbilical hoses at least as long as the tunnel. A tunnel would also allow MAV crews to discard their EVA suits in a thermally-conditioned, secure element for later mission re-use or scavenge, rather than discarding them on the surface. This protects the crew in a contingency scenario where the MAV engines fail to ignite; crew can simply retreat back through the tunnel to the habitable element for troubleshooting. Strictly speaking, a tunnel does not have to be retractable but one-time use options such as pyrotechnic detachment may not make sense for a long-duration mission where surface elements will be re-used or reconfigured over time.

One downside to tunnels is that they may be awkward when moving between elements at different elevations, as depicted in Figure 12, though it may still be safer than EVA crews climbing down an exposed ladder. Another disadvantage is that pressurized tunnels—or unpressurized tunnels with long umbilical hoses—will require a robust environmental control and life support system feeding the tunnel from at one or both of the two mated elements.

\section{Conclusion}

Based on the observations noted above, the following steps are recommended to minimize MAV cabin mass, thus reducing overall mission mass:

1) Limit MAV usage to 24 consecutive hours or less.

2) Abandon EVA suits in a surface asset and ascend in the MAV wearing IVA suits.

3) Limit MAV functionality to ascent only, rather than dual-use ascent/habitat functions.

4) Ingress/egress the MAV via a retractable tunnel to another pressurized surface asset.

\section{Acknowledgments}

Graphics provided courtesy of John Teter, Victor Dang, Tim Collins, Dan Miller, and David Paddock. EVA information provided courtesy of Natalie Mary. Gear ratio estimates courtesy of Walter Stephens and Ryan Whitley.

\section{References}

\footnotetext{
${ }^{1}$ Thompson, S. and Rucker, M., "Surface Vehicle Task 516: Two and Three Crew Mockup Configuration and Comparison Evaluation Final Report,” National Aeronautics and Space Administration, Lyndon B. Johnson Space Center, Houston, 2011.
} 
${ }^{2}$ SSP 50005/NASA-STD-3000, “International Space Station Flight Crew Integration Standard,” Revision C, International Space Station Program, National Aeronautics and Space Administration, Houston, 1999.

${ }^{3}$ JSC-47223, “ESPO Test 6: C-9 Facility Space Suit Interface Evaluation Test Report,” EVA Systems Project Office, National Aeronautics and Space Administration, Lyndon B. Johnson Space Center, Houston, 2009.

${ }^{4}$ CxP 7000, “Constellation Architecture Requirements Document (CARD)," National Aeronautics and Space Administration, Washington, 2010.

${ }^{5}$ NASA, “Technology Roadmaps, TA6: Human Health, Life Support, and Habitation Systems,” National Aeronautics and Space Administration, Washington, 2015. http://www.nasa.gov/offices/oct/home/roadmaps/index.html [cited 18 May 2015]

${ }^{6}$ SP-2010-3407, “Human Integration Design Handbook (HIDH),” National Aeronautics and Space Administration, Washington, 2010.

${ }^{7}$ Thompson, S., Litaker, H., Szabo, R., Howard, R., and North, D.,“Evaluation of the Altair Lunar Lander DAC-3 Interior Volume Configuration,” National Aeronautics and Space Administration. Lyndon B. Johnson Space Center, Houston, 2010.

${ }^{8}$ NASA-STD-3001, Volume 2, “NASA Space Flight Human-System Standard, Human Factors, Habitability, and Environmental Health,” Revision A, National Aeronautics and Space Administration, Washington, 2015.

${ }^{9}$ SP-2009-566, "Human Exploration of Mars Design Reference Architecture 5.0," National Aeronautics and Space Administration, Mars Architecture Steering Group, Washington, 2009.

${ }^{10}$ TP-2006-213726, “The Apollo Experience Lessons Learned for Constellation Lunar Dust Management,” National Aeronautics and Space Administration, Lyndon B. Johnson Space Center, Houston, 2006.

${ }^{11}$ NASA NPI 8020.7/NPD 8020.7G, "NASA Policy on Planetary Protection Requirements for Human Extraterrestrial Missions,” National Aeronautics and Space Administration, Washington, 2014. 